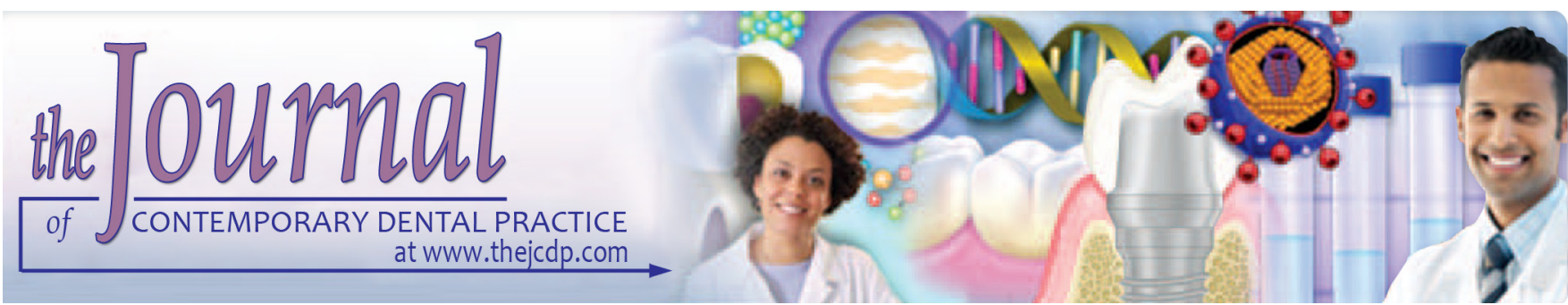

\title{
Evaluation of Caries Prevalence and Decayed-, Missing-, and Filled-teeth Values in Permanent Dentition in Children 7 to 10 Years Old-A Longitudinal Study
}

\author{
${ }^{1}$ Canga Mimoza, ${ }^{2}$ Malagnino A Vito
}

\begin{abstract}
Aim: To evaluate the correlation between age and caries development in permanent teeth, as well as to show the trends of decayed, missing, and filled teeth (DMFT) index in Albania.

Materials and methods: Subsequent observations hold from July 2016-July 2018. Our study included 393 children of the age range of $7-10$ years old. The children in the survey were divided into four groups according to their ages 7, 8, 9 and 10 years and these groups were considered separately. For the age group 7 years old we observed 110 children (28.13\%), for the age group 8 years old we observed 106 children (27.11\%), while for the age groups 9 years and 10 years old we observed $88(22.35 \%)$ and $89(22.41 \%)$ children, respectively.
\end{abstract}

Results: In our study, 393 children were selected and a total of 3128 molars were observed during 2 years time period. The strong influence on caries of the age group 9-10 years old is confirmed by $p$ value 0.002 . The results of our study show that the influence in caries manifestation decreases more at the age of 8-9 years old with a $p=0.014$. Caries prevalence was $28.3 \%$ in permanent dentition in children $7-10$ years old, while the DMFT index of our results was 3.46 .

Conclusion: Our results showed a prevalence of carious teeth at the age group 9-10 years old compared with the age group 8-9 years old. To reduce dental caries development and its increment in children of the age class $7-10$ years old we recommend the use of fluoride, a healthy non-cariogenic diet, and dental routine check-ups.

Clinical significance: Age has an important role in evaluating caries prevalence and DMFT index. Based on age, caries is more prevalent in children 9-10 years old, and the DMFT index resulted to be in high values equal to 3.46 .

${ }^{1}$ Department of Public Health, University Ismail Qemali, Vlore, Albania

2Department of Public Health Dentistry, University Gabriele D'Annunzio, Chieti, Italy

Corresponding Author: Canga Mimoza, Department of Public Health, University Ismail Qemali, Vlore, Albania, Phone: 00355676502493, e-mail: mimoza-canga@hotmail.com
Keywords: Age, Children, Dental caries, Decayed, missing, and filled teeth, Permanent teeth.

How to cite this article: Mimoza C, Vito MA. Evaluation of Caries Prevalence and Decayed-, Missing-, and Filled-teeth Values in Permanent Dentition in Children 7 to 10 Years Old-A Longitudinal Study. J Contemp Dent Pract 2019;20(1):8-12.

Source of support: Nil

Conflict of interest: None

\section{INTRODUCTION}

In children, permanent teeth play a vital role in eating, phonetics, esthetics and also as a space maintainer for permanent teeth. ${ }^{1}$ Oral health is an integral part of general health. ${ }^{2}$ Dental caries, because of its ubiquitous nature, remains one of the most prevalent afflictions of mankind. ${ }^{3}$

The early childhood caries is a combination of a child being infected with cariogenic bacteria, and the frequent ingestion of sugar is one of such diseases. ${ }^{4}$ Often problems in permanent teeth in the form of pain and swelling can cause distress to the child, leading to the inability to chew or speak properly or even may affect the appearance of a child. ${ }^{1}$ This disease not only causes damage to the tooth but is also responsible for several morbid conditions of the oral cavity and other systems of the body. ${ }^{5}$

The prevalence pattern of dental caries not only varies with age, sex, socio-economic status, race, geographical location, food habits, and oral hygiene practices but also within the oral cavity. ${ }^{6}$

Oral hygiene may be poor not only because of the carefree age and the emotional stresses of the child but also due to frequent intake of refined sugars, soft and sticky foods, shedding of deciduous teeth and the eruption of the permanent teeth. ${ }^{7}$

It is crucial to control the carious process by assessing and rendering the treatment required, along with spreading awareness about the prevention of dental 
caries. Many studies have been conducted worldwide which reveal the prevalence of dental caries among different populations. ${ }^{8-12}$

Several studies have claimed that all children are not at equal risk at developing dental caries. ${ }^{13-17}$ Healthy mouth enables an individual to eat, speak and socialize without active disease or discomfort and contribute to the general well-being. It is concerned with maintaining the health of craniofacial complex, teeth, and gums as well as the tissues of the face and head that surrounds the mouth. ${ }^{18}$

The main objective of this investigation was to assess the prevalence of dental caries among 7-10 years old children in permanent dentition.

\section{MATERIALS AND METHODS}

This is a longitudinal study with a controlled sample for 24 months. The children were selected randomly. The study was conducted in the period July 2016-July 2018. We controlled all the children's group in four clinics and selected 393 children, dividing them into four subgroups based on their age. The subgroups were 7-10 years old, and these groups were considered separately.

Our study was conducted in accordance with Helsinki declaration. ${ }^{19}$ Based on the Declaration of Helsinki issued by the World Medical Association, our research, which was on human participants, was formulated in experimental protocols. In our study, we anticipated the benefits and the potential risks to our sample, and after that, we took the consent of children's parents. Permissions were obtained in written form, which allowed us to perform the observations. Parents had the right to withdraw their children at any time.

The exclusion criteria were: children must not have orthodontic brackets, and they have to be within the age range of 7-10 years old. The age range can also be seen as a limitation of this study together with the sample size.

The study had no dropouts. The diagnosis of dental caries was performed through intraoral examination for each child. Intraoral examinations were performed through a dental mirror and exploration probe. Four doctors participated in our study. Two of them were examiners and two dentists who registered the children.

Based on the free screening we carried out as well as on the rapid verification of carious lesions, extracted and filled teeth, a high presence of morbidity was noticed.

Table 1: Correlation between caries manifestation and age groups 8-9 and 9-10 years old

\begin{tabular}{llll}
\hline Group -age & \multicolumn{2}{c}{ Sign. } & Cl 95\% \\
\hline 8- 9 years & 0.014 & 0.02 & 0.22 \\
9-10 years & 0.002 & 0.26 & 0.06 \\
\hline
\end{tabular}

\section{Study Design}

This descriptive and analytical research was designed as a longitudinal study. The sample was not kept under hospital observation. After doing the observation children were free to go. As we said, the participants were selected through simple randomization and were invited to take part in the research. The inclusion criteria were the age range of 7-10 years old. This study was approved by the University of Vlora, Albania.

\section{Statistical Analysis}

Statistical analysis was performed using IBM SPSS Statistics 23.0. Data were analyzed by post hoc LSD test in the analysis of variance (ANOVA). The significance level (a) was set at 0.05 with a confidence interval (CI) of $95 \%$.

\section{RESULTS}

In the present study, we analyzed the epidemiological state of permanent molars for 7-10 years old children. We divided them into four age groups 7-10 years old. After the verifications done with the children of these ages we found out that the manifestation of caries disease is inevitable and also it differs at different ages. The age of 9 years and 10 years old had fewer children so the deviations were bigger.

According to post hoc LSD test, the strongest influence in caries manifestation has the age of the children. This was seen on the intervals 8-9 years old and 9-10 years old. The strong influence on caries of the age group 9-10 years old, is confirmed by $p$ value 0.002 . The results of our study show that the influence in caries manifestation decreases more at the age of 8-9 years old with a $p=0.014$. The level of statistical significance was established at $\mathrm{p}<0.05$ (Table 1).

After performing statistical analysis in evaluating the frequency of carious teeth statistical significance was revealed $(p=0.034)$. It also showed that there was a significant difference $(p<0.05)$ in caries prevalence in relation to age between and within children's groups (Table 2).

Based on our data analysis caries prevalence was 28.3\% (Table 3).

According to our analysis DMFT index in permanent teeth for children 7-10 years old resulted to be 3.46. The percentages of carious, extracted and filled teeth based on age groups is also presented in the same analysis (Table 4).

Table 2: Relation between caries and the age group 7-10 years according to ANOVA

\begin{tabular}{llll}
\hline Group-age & Mean & $F$ & $p$ \\
Between age groups & 15.20 & 2.89 & 0.034 \\
Within age groups & 5.25 & & \\
\hline
\end{tabular}


Table 3: Distribution of carious, extracted and filled teeth in relation to age

\begin{tabular}{llllll}
\hline Age & Healthy & Carious & Extracted & Filled & Total \\
\hline 7 years old & 611 & 167 & 69 & 33 & 880 \\
8 years old & 479 & 222 & 45 & 102 & 848 \\
9 years old & 334 & 237 & 27 & 101 & 699 \\
10 years old & 261 & 260 & 92 & 88 & 701 \\
Total & 1685 & 886 & 233 & 324 & 3128 \\
$\%$ & 53.9 & 28.3 & 7.4 & 10.4 & 100 \\
\hline
\end{tabular}

For the age group, 7 years old, we observed $28.13 \%$ children, for the age group 8 years old we observed $27.11 \%$ children, while for the age groups 9 and 10 years old we observed $22.35 \%$ and $22.41 \%$ children, respectively. We can state that the percentage of observed teeth according to age range is higher in the group of 7 years old compared to the other age groups (Graph 1).

Based on our data, carious teeth are more prevalent than extracted or filled ones (Graph 2).

\section{DISCUSSION}

Caries of permanent teeth is among the most prevalent health problems of infants and toddlers. It can be considered an epidemic in lower-income families and underdeveloped parts of the world. ${ }^{20}$ Early dental screening is the key to improve infant oral health care. ${ }^{21}$

Dental caries is a common public health problem among 7-10 years old Albanian children from Vlora city, with a DMFT value 3.46. This value is considerably higher compared to reports from other developing countries.

Maintaining healthy permanent teeth is essential to a child's overall oral and general development. ${ }^{22}$

In the present study, were observed 393 children with 3128 molars. Based on our results there is a strong correlation between age and caries manifestation. The strongest correlation was achieved for the age group 9-10 years old with a $p=0.002$, while for the age 8-9 years old the $p$ value was 0.014 .

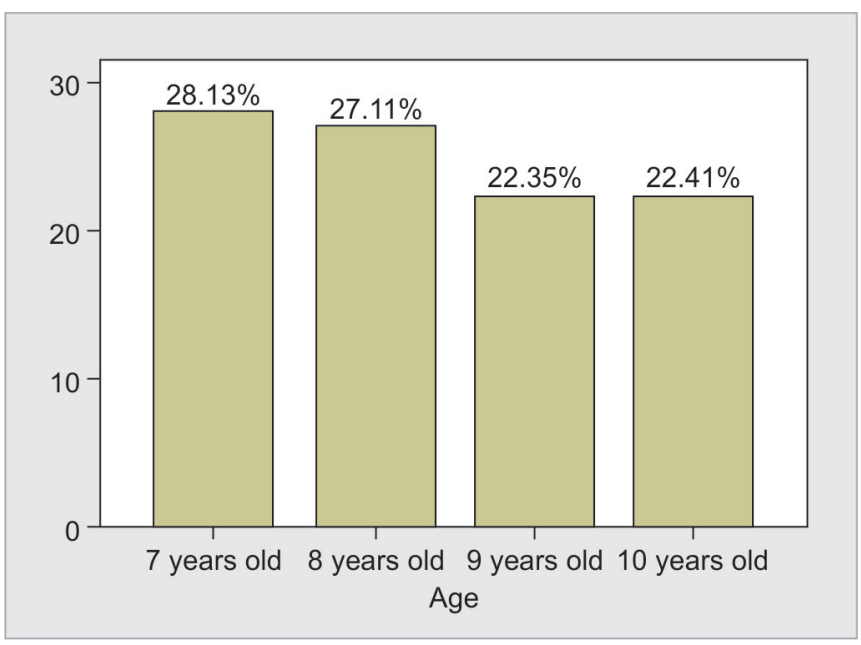

Graph 1: Shows the percentage of observed teeth according to age groups $7-10$ years
Table 4: DMFT index in permanent teeth of 7-10 years old children

\begin{tabular}{lclll}
\hline Age group & Carious & Extracted & \multicolumn{2}{l}{ Filled teeth DMFT } \\
\hline 7 years old & $5.4 \%$ & $2.2 \%$ & $1.05 \%$ & 3.46 \\
8 years old & $7.09 \%$ & $1.43 \%$ & $3.26 \%$ & \\
9 years old & $7.57 \%$ & $0.86 \%$ & $3.22 \%$ & \\
10 years old & $8.31 \%$ & $2.96 \%$ & $2.81 \%$ & \\
\hline
\end{tabular}

This means that our study proved dental caries increment if children get older. Similar data were reported by $\mathrm{Wyne}^{23}$ who stated that as the age of the children increases, they were exposed to cariogenic factors, more and more teeth become curious.

The same happens with extracted teeth which results showed that there are more extracted teeth at the age 10 years old. While the results of filled teeth achieved they highest level at the age 8 years old with 3.26\%.

An early first dental visit may ensure that the dentist can perform preventative measures such as the application of fluoride and fissure sealants, provide oral hygiene instructions and motivate the parents and their children regarding proper oral hygiene maintenance and dietary control as well as the importance of regular visits to the dentist. ${ }^{24}$

Parents play an important role in preventing dental caries, and they should take care of their children to minimize caries manifestation. According to Canadian study parents who believed permanent teeth were important had children with significantly lower caries rates than those who believed otherwise. ${ }^{25}$ Therefore parental knowledge appears to have a direct effect on the oral health of the child.

Fear and anxiety are the main reasons why children do not want to go to the dentist. Beside this parents together with their children should visit the dentist regularly and teach them to daily tooth brushing at least twice a day and to use the dental floss daily. ${ }^{26}$

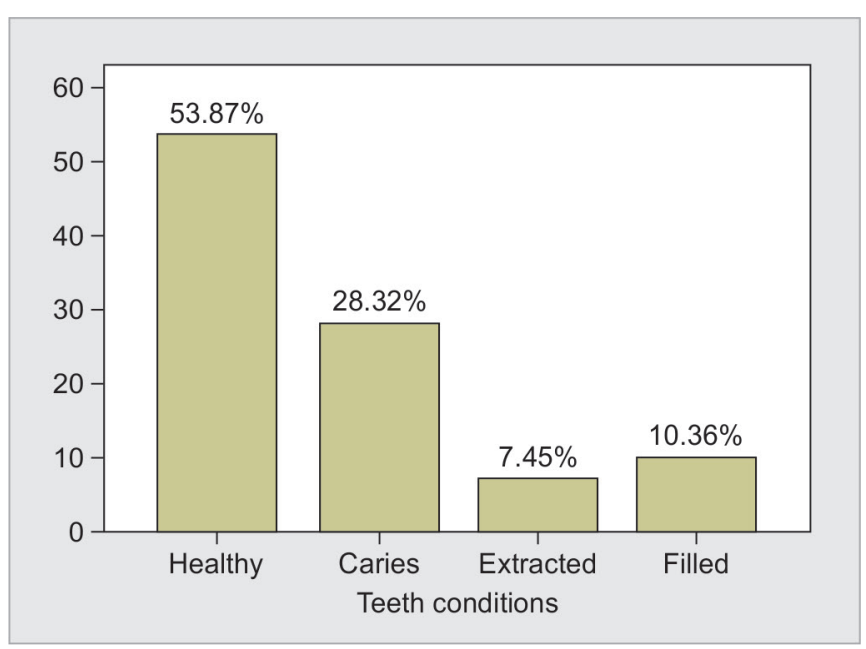

Graph 2: Shows in percentages the distribution of healthy, carious, filled and extracted teeth 
Nowadays, there is growing evidence supporting more 'biological' and fewer 'surgical' approaches to managing dental caries in permanent teeth. These biological methods include partial and stepwise caries removal procedures as well as techniques where no caries is removed. ${ }^{27}$

In order to reduce surgical approaches and dental caries development and its increment in children of the age range 7-10 years old, a systematic intervention for these age groups should be done. ${ }^{28}$ We recommend the use of fluoride, a healthy non-cariogenic diet, and dental routine check-ups. Also, food with a high content of carbohydrates should be avoided to minimize dental caries problem. ${ }^{29}$

The values of DMFT 3.46 obtained by our study are similar to the values obtained by Kunzel ${ }^{30}$ who found that DMFT for the Eastern European region was 4.1 and with the ones obtained by Radić ${ }^{31}$ in Croatia, where the DMFT value was 4.14 .

While, our DMFT index 3.46 is higher if we compare it with the values found by Angelillo ${ }^{32}$ in Italy 2.8 and Pieper $^{33}$ in Germany 1.24.

Findings of the current study proved that the DMFT value in the region of Vlore, Albania, was 3.46. This value is in contrast with the studies conducted by Andegiorgish, ${ }^{34}$ Adekoya-Sofowora, ${ }^{35}$ and Nurelhuda, ${ }^{36}$ who found that the total mean DMFT in Eritrea was 2.50, in Nigeria 0.14, followed by Sudan with a score of 0.42 .

James et al. ${ }^{37}$ observed that DMFT value in India was 3.14, which is relatively lower than the DMFT value we obtained.

Furthermore, the systematic dental health care in the Scandinavian countries has found that DMFT values are lower in comparison with European countries, for instance: in Denmark 0.6, in Sweden 0.8 and Norway 1.7. If we compare these data with the results obtained in our study, we can claim that our DMFT value presents an alarming situation about oral health care in Albania. ${ }^{38}$

According to Eaton, ${ }^{39}$ we should not make a direct comparison of the DMFT values, because studies may have different methodologies and different time periods of data collection.

Based on caries prevalence and DMFT index, obtained in our study children of the age class 7-10 years old are riskier. We should also state that the limitations of our study are the sample size, which was not large enough to generalize the results and the age range of the children.

We recommend that efforts should be done in promoting oral health care. Raising parents awareness, the use of fluoride, brushing the teeth regularly at least three times a day and minimizing the use of carbohydrates will also help reduce dental diseases. As well as appropriate oral hygiene measures are needed for this age groups of children in preventing dental caries.

\section{CONCLUSION}

Within the limits of the present study, we can state that children of the age group 7-10 years old have more carious teeth than extracted or filled ones. This is an extremely alarming situation which needs immediate intervention. Our study proved that there is a strong correlation between age and caries development. The high values of DMFT index obtained showed that dental caries remains a problem that's why preventing measures should be taken.

\section{CLINICAL SIGNIFICANCE}

Age has an important role in evaluating caries prevalence and DMFT index. Based on age, caries is more prevalent in children 9-10 years old and the DMFT index resulted to be in high values equal to 3.46 .

\section{ACKNOWLEDGMENT}

Authors would like to thank Professor Vito Malagnino for his support and contribution in conducting this study.

\section{REFERENCES}

1. Setty JV, Srinivasan I. Knowledge and Awareness of Primary Teeth and Their Importance among Parents in Bengaluru City, India. Marwah N, editor. International Journal of Clinical Pediatric Dentistry 2016;9:56-61.

2. Yewe-Dyer M. The definition of oral health. Br Dent J 1993;174:224-225.

3. Almoudi N, Salako NO, Massoud I. Caries experience of children aged 6-9 years in Jeddah, Saudi Arabia. Int J Pediatr Dent 1996;6:101-105.

4. Mahejabeen R, Sudha P, Kulkarni SS, Anegundi R. Dental caries prevalence among preschool children of Hubli: Dharwad city. J Indian Soc Pedod Prev Dent 2006;24:19-22.

5. World Health Organisation. Dental Health published in World Health, Cited in Chakraborty M, Saha JB, Bhattacharya RN, Roy A, Ram R. Epidemiological correlates of dental caries in an urban shun of West Bengal. Indian J of Pub Helth 1997; 41(2):56,1981

6. Saravanan S, Madivanan I, Subashini B, Felix J W. Prevalence pattern of dental caries in the permanent dentition among school children. Indian J Dent Res 2005;16:140-146.

7. Alvarez-Arenal A, Alvarez-Riesgo JA, Peña-Lopez JM, Fernandez-Vazquez JP. DMFT, dmft and treatment requirements of school children in Asturias, Spain. Community Dent Oral Epidemiol 1998;26:166-169.

8. Pandit IK, Singh M, Nikhil Srivastava N. Prevalence of dental caries in mixed dentition period amongst children of Yamuna Nagar District (Haryana). J Ind Dent Assoc 2000;71:23-24.

9. Chawla HS, Gauba K, Goyal A. Trend of dental caries in children of Chandigarh over the last sixteen years. J Indian Soc Pedod Prev Dent 2000;18:41-45.

10. Brukiene V, Aleksejuniene J. An overview of oral health promotion in adolescents. Int J Paediatr Dent 2009;19:163-171.

11. Tewari A, Chawla HS. A study of prevalence of dental caries in an urban area of India. J Indian Dent Assoc 1997;49:231-234. 
12. Bhardwaj VK, Vaid S, Chug A, Jhingta P, Negi N, Sharma D. Prevalence of dental caries among five-year-old school children in Shimla city, Himachal Pradesh. Eur J Gen Dent 2012;1:34-38.

13. Peterson PE, Steengard M. Dental caries among urban school children of Madagascar. J Comm Dent Oral Epi 1988;16: 163-166.

14. Ramos-Gomez FJ, Huang GF, Masouredis CM, Braham RL. Prevalence and treatment costs of infant caries in Northern California. ASDC journal of dentistry for children. 1996;63(2):108-112.

15. Holbrook WP, de Soet JJ, de Greaff J. Prediction of dental caries in preschool children. J Caries Res 1993;27:424-430.

16. Holm AK. Caries in the preschool child- international trends. J Dent 1990;18:291-295.

17. Kuriakose S, Joseph E. Caries prevalence and its relation to socioeconomic status and oral hygiene practices in 600 preschool children of Kerala, India. JISPPD 1999;17:97-100

18. Samire B. Textbook of Orthodontics. Philadelphia, PA: Harcourt, India 2001. 460-476 p.

19. Williams JR. The Declaration of Helsinki and public health. Bulletin of the World Health Organization. 2008;86(8):650-652.

20. Bernabé E, Sheiham A. Age, period and cohort trends in caries of permanent teeth in four developed countries. American journal of public health. 2014 Jul;104(7):e115-121.

21. Jyothsna V S, Srinivasan I. Permanent teeth: Paediatrician's perspective-A survey, International Journal of Dentistry Research 2017;2(2):40-43.

22. Pinkham JR. Examination, diagnosis, and treatment planning of the infant and toddler. In: Casamassimo PS, Warren JJ, editors; Paediatric dentistry infancy: through adolescence. 4th ed. New York, NY: Elsevier Inc 2005. p. 206-219.

23. Wyne AH. The bilateral occurrence of dental caries among 12-13 and 15-19 year old school children. J Contemp Dent Pract. 2004;5(1):42-52.

24. Al-Samadani KH, Ahmad MS. Prevalence of first permanent molar caries in and its relationship to the dental knowledge of 9-12-year olds from Jeddah, kingdom of Saudi Arabia. ISRN dentistry. 2012 Mar 11;2012.

25. Schroth RJ, Brothwell DJ, Moffatt ME. Caregiver knowledge and attitudes of preschool oral health and early childhood caries (ECC) Int J Circumpolar Health 2007 Apr;66(2):153167. [PubMed]

26. Bastos RS, Carvalho ES, Xavier A, Caldana ML, Bastos JR, Lauris JR. Dental caries related to quality of life in two Brazil- ian adolescent groups: a cross-sectional randomised study. Int Dent J 2012;62:137-143.

27. Innes NP, Evans DJ. Modern approaches to caries management of the permanent dentition. Br Dent J 2013 Jun;214(11):559-566.

28. Perinetti G, Varvara G, Esposito P. Prevalence of dental caries in schoolchildren living in rural and urban areas: results from the first region-wide Italian survey. Oral Health Prev Dent 2006;4:199-207.

29. Ostberg AL, Halling A, Lindblad U. Gender differences in knowledge, attitude, behavior and perceived oral health among adolescents. Acta Odontol Scand 1999;57:231-236.

30. Kunzel W. Zur Konversion der epidemiologischen Zucker/ Caries-relation in Europe. Oralpropphylaxe 2001;23:66-70.

31. Radić M, Benjak T, Dečković Vukres V, Rotim Ž, Filipović Zore I. Presentation of DMF Index in Croatia and Europe. Acta stomatologica Croatica. 2015 Dec 21;49(4):275-284.

32. Angelillo IF, Anfosso R, Nobile CG, Pavia M. Prevalence of dental caries in schoolchildren in Italy. Eur J Epidemiol 1998;14:351-357.

33. Pieper K, Schulte AG. The decline in dental caries among 12- year-old children in Germany between 1994 and 2000. Community Dent Health 2004;21:199-206.

34. Andegiorgish AK, Weldemariam BW, Kifle MM, Mebrahtu FG, Zewde HK, Tewelde MG, et al. Prevalence of dental caries and associated factors among 12 years old students in Eritrea. BMC oral health. 2017 Dec;17(1):169.

35. Adekoya-Sofowora CA, Nasir WO, Oginni AO, Taiwo M. Dental caries in 12-year-old suburban Nigerian school children. African Health Sciences. 2006;6(3):145-150.

36. Nurelhuda NM, Trovik TA, Ali RW, Ahmed MF. Oral health status of 12-year-old school children in Khartoum state, the Sudan; a school-based survey. BMC oral health. 2009 Dec;9(1):15.

37. John JR, Daniel B, Paneerselvam D, Rajendran G. Prevalence of dental caries, oral hygiene knowledge, status, and practices among visually impaired individuals in Chennai, Tamil Nadu. International journal of dentistry. 2017;2017.

38. Fathalla LH. Caries prevention strategies practiced in Scan-dinavia: a literature study: bachelor thesis [Internet]. Malmo: Malmo University, Faculty of Odontology 2011; p. 8-19.

39. Eaton KA, Newman HN, Bulman JS. National mean DMFT scores for Western European 12 years-olds: are they comparable? J Dent Res 2003;334:82 